\title{
Urte bat baino gutxiagoko umeengan agertutako nerbio-sistema zentraleko tumoreak: berrikuspena Gurutzetako Unibertsitate Ospitalean eta literaturan
}

\author{
Central Nervous System (CNS) tumors in an under 1 year-old population. A \\ review of our series in Cruces University Hospital and of the literature
}

Edurne Ruiz de Gopegui ${ }^{1}$, Gaizka Bilbao ${ }^{1}$, Lara Galbarriatu ${ }^{1}$, Goyo Catalán ${ }^{1}$, Miguel GarcíaAriza $^{2}$, Itziar Astigarraga ${ }^{2}$, Laura Zaldumbide ${ }^{3}$, Ainara Dolado ${ }^{4}$, Iñigo Pomposo ${ }^{1}$

\author{
1. Neurokirurgia Zerbitzua \\ 2. Pediatria Zerbitzua, \\ 3. Anatomia Patologikoa Zerbitzua \\ 4. Erradiologia Zerbitzua. \\ Gurutzetako Unibertsitate Ospitalea
}

Harreman-helbidea: Edurne Ruiz de Gopegui. Neurokirurgia Zerbitzua. Gurutzetako
Unibertsitate Ospitalea. Gurutzeta Enparantza, z/g. 48130. Barakaldo (Bizkaia)
mirenedurne.ruizdegopeguiruiz@osakidetza.eus

Laburpena

Lan honen helburua Gurutzetako Unibertsitate Ospitalean urtebete baino gutxiagoko umeengan agertu diren nerbio-sistema zentraleko tumoreen kasuak eta haien gaineko literatura berrikustea izan da. Urtebete edo gutxiagoko umeengan 2001-2016 bitartean diagnostitatutako NSZko tumoreen kasuak ikertu dira. Haien diagnosi-adina, kokapena, tratamendu neurokirurgikoa, hidrozefaliaren agerpena, biziraupena eta gaixotasunaren segimendua berrikusi dira. Gurutzeta Unibertsitate Ospitaleko Onkologia-Hematologia-Pediatriako Unitatean 2001-2016 urteen artean artatutako NSZko tumorea izan zuten 14 urtetik beherako 158 pazienteen artean, urtebetetik beherako 16 tratatu ziren. Hamalau tumore supratentorialak izan ziren, bat infratentoriala eta beste bat ornomuin zerbikalean zegoen kokaturik. Kasu batean, diagnosia jaio aurrekoa izan zen. Anatomia patologikoari dagokionez, hamar gliomak izan ziren (bi gradu altukoak eta zortzi gradu baxukoak), hiru PNET (tumore neuroektodermiko primitiboa) infratentorialak, plexu koroideetako papiloma atipikoa bat, teratoide rabdoide atipiko bat, PNET supratentorial bat eta beste bat tumore neuroektodermiko melanozitikoa. Hamalau pazienterengan prozedura kirurgikoren bat gauzatu zen, eta hamabi kasutan kraniotomia eta neurri desberdinetako erauzketa izan ziren. Talde horretako bik prozedura kirurgiko bat baino gehiago behar izan zuten. Beste paziente birengan, kraniotomiaren ordez, biopsia estereotaktikoa baino ez zen egin orratz baten bitartez, diagnosia izanik helburu bakarra. Kirurgia ez zen mahaigaineratu gaixo biren kasuan, nerbio optikoko gliomen susmoa zegoelako. Gradu altuko tumoreetan, bost urteko biziraupena izan zuen kasu batean izan ezik, besteak ez ziren hain epe luzera heldu. Bi prozedura kirurgikoan bertan hil ziren. Gradu baxuko tumoreak zituzten hamarretik bederatzi bizirik daude oraindik, batez besteko 3,8 urteko biziraupenarekin. Bestea, 4,3 urte iraun eta gero, hil egin zen. Urtebete baino gutxiago duten umeen garuneko tumoreen ezaugarriak (portaera, pronostikoa...) eta nagusiagoenak nahiko desberdinak dira; talde haren ezaugarriak bereziak dira alegia. Gradu altuko tumoreetan, pronostikoak oso aurkakoa izaten jarraitzen du, hobetzeko ahaleginean ekin arren. 
Ruiz de G., Bilbao, Galbarriatu, Catalán, García-A., Astigarraga, Zaldumbide, Dolado eta Pomposo

Gako hitzak: Garuneko sortzetiko tumoreak, umeen NSZko tumoreak, jaioberriko periodoa, glioma, adin pediatrikoa

\begin{abstract}
Here, we present a review of CNS tumors diagnosed in an under one year-old population in Cruces University Hospital. We studied under one year-old patients diagnosed between 2001 and 2016 in Cruces University Hospital, and reviewed location, approach, presence/absence of hydrocephalus, survival and follow-up. Sixteen under one year-old patients were diagnosed among a series of 158 $<14$ year old children during that period. Fourteen patients had supratentorial tumors, 1 had an infratentorial tumor and one had an intraspinal cervical tumor. The sample included 10 gliomas (2 high grade, 8 low grade), 3 infratentorial primitive neuroectodermal tumors (PNET), 1 atypical choroidal plexus papilloma, 1 atypical teratoid/rhabdoid tumor, 1 supratentorial PNET and 1 neuroectodermal melanocytic tumor. Fourteen patients were operated on; in twelve of them we employed craniotomy with variable resection. Two of these needed consecutive craniotomies. In two patients, stereotactic biopsy was carried out due to the suspicion of an optic pathway glioma. Two patients were not amenable for surgical resection or biopsy and thus were not operated. Except for one patient who is alive after a follow-up of five years, the rest of the patients diagnosed of highgrade tumors died during follow up, two of them passing away during the surgical procedure. All patients diagnosed with a low-grade tumor are alive with a median follow-up of 3.8 years, except for one patient who died four years post-operation. Congenital tumors show a different pattern than tumors in other pediatric ages. The prognosis of high grade lesions continues to be discouraging despite apparent improvements.
\end{abstract}

Keywords: congenital brain tumor, child brain tumor, neonatal period

Bidalia: 2017ko martxoaren 24an.

http://doi.org/10.26876/osagaiz.1.2017.77

Onartua: 2017ko maiatzaren 2an.

\title{
1. Sarrera
}

Hainbat autoreren arteko eztabaida bizia ikus daiteke literaturan sortzetiko tumoreak adinaren arabera sailkatzeko orduan. Sailkapenetan gehien zabaldu den bat Jellingerena (1) da. Autore horrek 3 mailatan sailkatzen ditu: benetakoak, lehenengo 6 asteetan diagnostikatuak; seguruenik sortzetikoak, lehenengo 6 hilabeteetan agertutakoak, eta agian sortzetikoak, lehenengo urtea bete baino lehen diagnostikatzen direnak.

Oso tumore arraroak dira, baina leuzemiaren atzetik adin-talde horretan gehien agertzen direnak dira, sarrienak tumore solidoen artean. Gaur egun, haurdun dauden emakumeengan egiten den ohiko kontrolari esker, diagnosia jaio aurrekoa izaten da askotan. Horrek erditzeko momentua aurretiaz programatzea eta haur jaioberriaren ezaugarriei egokitzea a halbidetzen du. Klasikoki, teratoma deskribatu izan da NSZko sortzetiko tumoreen artean sarrien gertatzen dena, eta haren kokapena supratentoriala ohi da urtebetetik aurrera. Tumore horiek ematen duten sintomatologia urria da adin horretan kaskezurrak duen elastikotasuna dela-eta, eta, izan ere, ezaugarri horrek egiten du diagnosiaren orduan tumoreak oso handiak izatea eta ondorioz, tratamendua zailagoa bihurtzea. Gradu altuko tumoreen kasuan, pronostikoak oso goibela izaten jarraitzen du pazienteak tratatuak izan arren eta, oro har, haien bizi-itxaropena oso gutxitan luzatzen da urtebete baino haratago. Halere, badago epe hori gainditzen duen tumore-kasu gutxiko multzorik, baina, helduaroari begira, pronostikoak ilun jarraitzen du.

Gaur egun, kirurgiaren inguruko hobekuntzei eta zaintza intentsiboei esker, baina baita neurokirurgia eta neuroonkologia arloetan izandako aurrerapenei esker ere, biziraupen luzeak espero daitezke gradu baxuko tumore edo plexu koroideetako papilomen kasuetan. 


\section{Material eta metodoak}

Kasu-serie ikerketa honetan, 2001-2016 bitartean Gurutzetako Unibertsitate Ospitalean urtebete edo gutxiagoko umeengan diagnostikatutako NSZko tumoreen kasuak ikertu dira. Haien diagnosi-adina, kokapena, tratamendu neurokirurgikoa, hidrozefaliaren agerpena, biziraupena eta gaixotasunaren segimendua berrikusi dira. Horretaz gain, gai honi buruzko literaturaren errebisio bat egin da (1. taula).

\section{Emaitzak}

Gurutzeta Unibertsitate Ospitaleko Onkologia-Hematologia-Pediatriako Unitatean 2001-2016 urteen artean NSZko tumoreengatik artatutako 14 urte arteko 158 umetatik, urtebetetik beherako 16 paziente tratatu ziren.

Hamasei pazienteetatik, hamalauk tumore supratentoriala izan zuten, batek lesio infratetoriala eta azkenak ornomuinean bosgarren ornoaren inguruan. Hamalau gaixori prozedura kirurgikoren bat gauzatu zitzaien, hamabiri kraniotomia eta neurri desberdinetako erauzketa. Talde horretako bik ebakuntza bat baino gehiago izan zuten. Beste paziente biri, kraniotomiaren ordez, biopsia estereotaktikoa baino ez zitzaien egin orratz baten bitartez, diagnosia izanik helburu bakarra. Gaixo birengan ez zen kirurgia mahaigaineratu, bide optikoko gliomen susmoa zegoelako.

Zazpi gaixok hidrozefalia izan zuten, eta haietako seik, tratamendua jaso: batek bentrikulostomia eta beste bostek deribazio bentrikulo-peritoneala (DBP). Tumore eta gaixoen berezko ezaugarriak kontuan hartuta, hiru kasutan deribazioa aldatu behar izan zen: behin kasu batean, eta bitan beste bietan. Hidrozefalia tratatu ez zen zazpigarren pazientean gaixotasuna progresioan zegoela iritzi eta zainketa paliatiboetako fasean zegoela onartu zen.

Gradu altuko tumoreak izan zituzten zazpi gaixoetatik batek bederatzi urteko biziraupena izan zuen. Gradu baxuko tumoreak izan zituzten bederatzi umeetatik, egun zortzik bizirik diraute, biziraupenaren batezbestekoa 3,8 urte delarik, eta bederatzigarrena 4,5 urtera hil zen. Paziente bi kirofanoan bertan hil ziren.

Anatomia patologikoari dagokionez, \% 62,5ek gliomak izan zituzten, zortzik gradu baxukoak eta bik altukoak. Gainerakoek beste tumore mota batzuk izan zituzten: PNET $(n=2)$, plexu koroideetako tumore atipikoa $(n=1)$, tumore neuroektodermiko melanozitikoa $(n=1)$, tumore teratoide rabdoide atipikoa $(n=1)$ eta meduloblastoma $(n=1)$.

Hona hemen adibideko kasu batzuk:

\section{Lehenengo kasua}

Hiru hilabeteko umea Larrialdi Zerbitzura eraman zuten gurasoek, azken egunetan oka egiten zuelako eta ahultzea nabarmena zelako. Ordu arte umearen garapena normala izan zen. Azterketa fisikoan fontanela beteta eta tentsioz ikusirik, ordenagailu bidezko tomografia axiala (OTA) egin zitzaion: ezkerreko hemisferioko tumorea diagnostikatu zitzaion, burmuinetik zerebelorantz zabaltzen zena. Diagnostikoa erresonantzia magnetikoaren (EM) bidez egiaztatu zen eta kirurgia proposatu zitzaion familiari: kraneotomia eta biopsia irekia. Ebakuntza osteko egoera ezegonkorra izan zen eta umea estatus epileptiko kontrolaezinean sartu zen. Anatomia patologikoak tumore teratoide rabdoide atipikoa zela erakutsi zuen ( 1 eta 2 . irudiak). Umearen egoera eta diagnostikoa zein ziren ikusirik, eta familiarekin adostuta, tratamenduari muga jartzea erabaki zen, eta umea 2 hilabete pasa eta gero hil zen. 
1. irudia. Hematoxilina-eosina tinzioarekin egindakoa (x400). Kohesio gabeko zelularitatea ikus daiteke, ezaugarri rabdoidea erakusten duena. Zitoplasma zabalak ikus daitezke baita nukleo atipikoak ere.

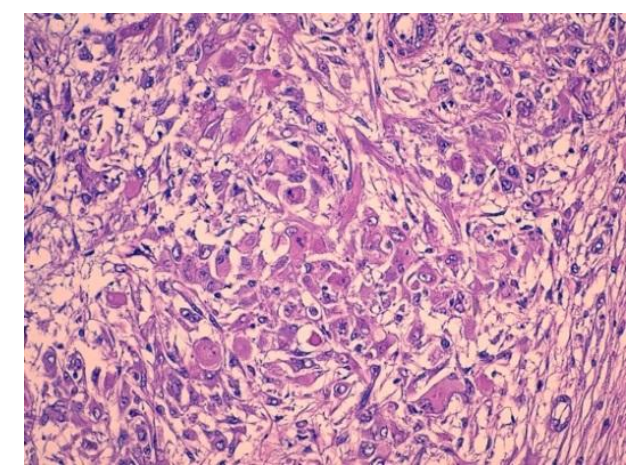

2. irudia. INI-1 markatzailea ez da adierazten tumorearen zelulako nukleoetan ez eta endotelio baskularrean ere (immunohistokimika, x200).

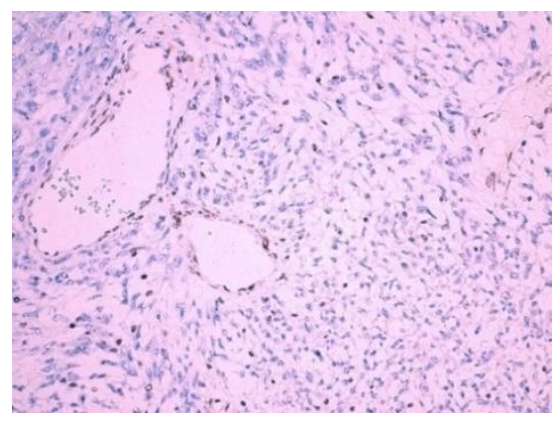

\section{Bigarren kasua}

Kontrol gabeko haurdunaldia eta gero, 35. astean ekografia baten bidez fetuak EMaren bidez burmuineko tumore bat zeukala egiaztatu zen (3. irudia). Diagnosia eta berehala, erditze baginala antolatu zen. Umeak $2.750 \mathrm{~g}$ pisatu zuen (p90), $47 \mathrm{~cm}$ neurtu zuen (p50) eta perimetro zefalikoa $34,7 \mathrm{~cm}$-koa (p75) izan zen. Jaiotzean, aurkikuntza bakarra fontanela zabala zen, beste sintoma edo defizit neurologikorik gabe. Kraneotomia eta biopsia irekia proposatu zitzaien gurasoei, 12. egunean egin zirenak. Anatomia patologikoak astrozitoma anaplasikoa zela baieztatu zuen eta ostean kimioterapia hasi zuen Euro-Infant HGG 2008 protokoloari jarraituz. Konplikazio larriak pairatu zituen, infekzioso eta hematologikoak batez ere, baina baita krisi epileptikoak ere. Bi hilabete pasa eta gero hil zen, eta OTAn tumorearen kontrol gabeko hazkundea ikusi zen.

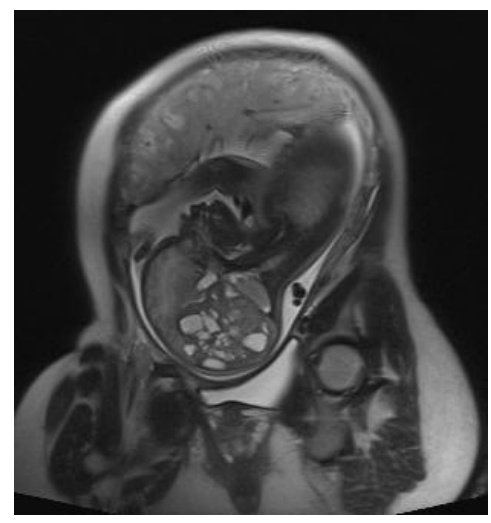

3. irudia. Erresonantzia magnetiko fetala, 35. astean eginda. HASTE sekuentzia, plano sagitalean. Garuneko eskuineko hemisferioko lobulu okzipital, tenporal eta parietalean $7 \times 6,5 \times 5$ $\mathrm{cm}$-ko tumorea agertzen da. Masa-efektu handia sortzen du: alboko bentrikulua aurrerantz bultzatzen du, garun-enborra kontrako alderantz eta alde bereko zerebelo hemisferioa beherantz, hemimeganentzefalia sorraraziz. Haren seinalea oso heterogeneoa da, alde solido zein kistikoekin: kiste txiki asko ditu barnean, foku hemorragiko ugarirekin. Tumorearen parte solidoa kanpoaldean dago: seinale baxua dauka eta difusioa murrizten du. Aukera diagnostikoak teratoma, tumore neuroektodermiko primitiboa, tumore teratoide rabdoidea eta glioblastoma dira. 


\section{Hirugarren kasua}

Lau hilabeteko ume bati logura, oka errepikakorrak eta buruaren neurriz kanpoko hazkundea nabaritu zioten astebeteko epean. Ekografiak burmuineko tumore hemisferiko bat zuela erakutsi zuen, kistez betetakoa. Drainatze-tutua jarri zitzaion urgentziaz bentrikuluan, garezur barneko presioa jaisteko. EMak egiaztatu egin zuen diagnostikoa eta familiari kirurgiaren bitartez lesioaren erauzketa partziala proposatu zitzaion. Ebakuntzaren ostean, umeak hidrozefalia pairatu zuen eta hainbat ebakuntza egin behar izan zitzaizkion hurrengo asteetan arazoa konpontzeko ahaleginetan. Horrez gain, estatus epileptikoa izan zuen eta ezkerreko hemiparesia. Anatomia patologikoak glioblastoma multiformea zela adierazi zuen. Familiaren desioz, tratamendua mugatzea erabaki zen eta azkenean, umea 9 hilabeterekin hil zen.

\section{Eztabaida}

1951. urtean, Arnstein izan zen lehen aldiz jaioberrian garuneko tumorea deskribatu zuena: egun biko ume batetan diagnostikatu zen plexu koroideetako angioma kabernosoa. Izatez minbizia ez zen arren, hurrengo urteetan ume koskorrengan agertuko ziren tumoreen sailkapen desberdinei atea ireki zien. "Sortzetikoa» izenordaina bizitzako lehen bi hilabeteetan agertzen direnentzat gorde da (2-4), nahiz eta jakin tumore horien jarrera desberdina dela urtebete baino gehiago duten umeengan diagnostikatzen direnekin konparatuta. Horregatik, autore batzuentzat epemuga urtebetekoa litzateke (1). Oro har, NSZko benetako sortzetiko tumoreak oso arraroak dira, guztien \% 0,5-1,9 (5).

Gaur egun, diagnosia fetua umetokian dagoela egin daiteke batzuetan, haurdunei hirugarren hiruhilekoan sistematikoki egiten zaien ekografiari esker. Horregatik, erditzeko momentua planifika daiteke, jaioberriak behar izango duen arretarekin batera. Ez da deskribatu tumore hauen umetoki barneko kirurgiarik.

Azterketa fisikoan ikusiko diren zeinuen artean garezurraren perimetroaren hazkundea da, beste sintoma neurologiko barik, gehien agertzen den aurkikuntza (6). Adin gutxiko umeen burezurreko malgutasunak egiten du hori posible, eta, horrela, tumoreak tamaina handikoak izatera hel daitezke sintomak eman aurretik (7). Datu horri gehitu egin behar zaio garatu gabeko burmuinek dituzten plastizitatea eta errekuperatzeko gaitasuna.

Neurokirurgia Pediatriakoko Nazioarteko Elkarteak (ISPN) (8) elkarlaneko galdeketa bat antolatu zuen beren bizitzako lehen urtean garuneko tumorea diagnostikatu zitzaien 886 pazienterekin. Gaur egun, tumore horiei buruz dakiguna, hein handi batean, dokumentu horretan agertu ziren datuei esker izan da: haien epidemiologia, anatomia patologikoaren araberako sailkapena, kokapena edota zer generori kalte egiten dioten gehiago. Gehienak astrozitomak izan ziren (\% 75 gradu baxukoak). Ependimomak, plexu koroideetako tumoreak, PNET eta teratomak \%11, \%11 eta \%7,7ko portzentajeak izan zituzten hurrenez hurren. Emaitza horiek bat datoz beste batzuek argitaratu dituztenekin (9). Harrigarria da plexu koroideetako tumoreak denen \% 1,2 baino ez izatea, eta 4 teratoide rabdoide atipiko bakarrik daudela 195 tumoreen artean (2. taula).

Ruiz de G., Bilbao, Galbarriatu, Catalán, García-A., Astigarraga, Zaldumbide, Dolado eta Pomposo

bezalaxe. Halere, bizitzako bigarren urtetik gora infratentorialen maiztasuna gora doa eta horrela iraungo du haurtzaro osoan (8). Ornomuineko tumoreak arraroagoak dira umeengan (\% 3 inguru) (11), eta are gutxiago jorratzen ari garen adin-taldean. Beraz, deigarria iruditzen zaigu gure seriean horrelako bat aurkitzea.

Pronostikoa oso aldakorra da, betiere serieen arabera. Urtebete eta bost urte arteko biziraupena $\% 45$ etik \% 85era eta \% 21etik \% 81era deskribatu izan da hurrenez hurren, autoreen arabera. Young eta Johnstonek (12) jakitera ematen dituzten emaitzak bikainak dira, haien seriean gradu baxuko tumore asko sartu baitira.

Bizi-kalitatea kontuan hartzen bada, serie batzuetan bakarrik ematen da jakitera, eta aldakortasun handia dago haien artean irizpideari dagokionez, ez baitago era objektiborik parametro hori 
neurtzeko adin honetako pazienteetan. Chung (13) eta Zuccarok (14) emaitza bikainak dituzte, haien serieetako gaixoen \% 69 eta \% 76 baitira, hurrenez hurren, bizimodu normala egiteko gai direnak. Aldiz, ISPNk egindako inkestan, gaixoen \% 24 bakarrik dira funtzionalki bizimodu normala izango dutenak eta \% $25 \mathrm{ek}$ krisi epileptikoak jasango dituzte. Serie horietan ez dute tresna estandarrik erabiltzen pronostiko funtzionala neurtzeko.

Azken bi hamarkadetan, ume hauek dituzten garuneko tumoreen tratamenduek aurrerapauso nabarmena izan dute. Hobekuntza hori zenbait faktoreri esker izan da, batez ere gaixotasunaren eta umeen arretari buruzko ezagutza handiagoari esker, batik bat neurokirurgia, onkologia edo arreta berezien ikuspuntutik $(10,15)$. Kirurgia aldetik, tumore hauen erauzketa osoa zaila da haien ezaugarri propioengatik, batez ere haien tamainagatik eta odola isurtzeko gaitasunagatik, duten aferentzia eta eferentzia baskularrengatik. Horri umeek duten bolemia $(70 \mathrm{ml} / \mathrm{kg})$ gehitu behar zaio. Izan ere, tumorea erauzteko unean bolemiaren \% 5-10 galtzeak oso ondorio kaltegarriak ekar ditzake, heriotza barne. Arrazoi horiengatik familiak jakin egin behar du prozedura kirurgikoak berezko heriotzaarriskua duela, eta gure seriean, beste batzuetan jasotzen den bezala, gaixoak hil egin dira kirofanoan (7). Literaturan irakurtzen diren hilgarritasun-tasak \% 0tik (16) \% 33ra (17) doaz.

Tratamendu desberdinen onura hainbat serietan jaso izan da. Izan ere, Duffnerrek (18) bere serie prospektiboan, 36 hilabete baino gutxiagoko multzo batean erakutsi zuen pronostikoa hobea zela, era esanguratsuan, tumorea erabat erauzten zenean, hori gertatzen ez zen kasuekin konparatuta. Idatzi izan da, era berean, kimioterapia tumoreen hazkundea kontrolatzeko gai dela, eta gainera, ez duela kalte kognitiborik eragiten, erradioterapiak egiten duenaz beste. Hori dela-eta, gaur egungo tratamendu-protokoloetan onartzen da, behar izanez gero, erradioterapia atzeratu beharra dagoela, gutxienez umeak 3 urte dituen arte.

Hala ere, paziente hauentzako tratamendu lagungarrien protokoloak garatzea erronka bat da oraindik gaur egun, adinak mugatzen baitu ume haziagoengan arazo barik emango liratekeen tratamendu zehatz batzuk ematea. Lehen tratamendu-protokoloen belaunaldia (baby-brain) 80ko hamarkadan garatu zen eta gero oso baliagarria izan den informazioa atera da haietatik. Bigarren belaunaldiko protokoloetan, 90eko hamarkadan diseinatuak, ez dira urtebete baino gazteagoak diren gaixoak aipatu ere egiten, bai kimioterapia-dosi altuak behar izaten zituztelako, ostean ama-zelulen erreskatea izateko, edo bai erradioterapiaren laguntza behar izaten zutelako. (15) 2008tik aurrera garatu diren protokoloek behintzat paziente horiek aipatu eta haientzat tratamendu-aukerak ematen dituzte; pronostikoa histologia mota eta tumorearen neurriaren araberakoa izaten da.

Amaitzeko, etika eta osasunaren aldetik, azpimarratzekoa da tumore hauek jaio aurretiko aldian diagnostikatzeak senideentzat duen garrantzia (19).

\section{Ondorioa}

Urtebete baino gutxiago duten pazienteengan gertatzen diren NSZko tumoreak oso gaixotasun arraroak dira eta gaur egun oraindik diagnostikoa egiteko eta tratamendua emateko orduan izaten dira erronka nabarmenenak. Tratamendu osoa egin ahal izan arren, gradu altukoek egun pronostiko goibela ohi dute. Erreferentzia-ospitaleen arteko datu-basea sortzea interesgarria litzateke hain ezezagun diren faktoreentzako ebidentzia handiagoa lortzeko.

\section{Erreferentzia bibliografikoak}

1. Jellinger K, Sunder-Plassmann M. Connatal intracranial tumours. Neuropadiatrie. 1973; 4(1): 46-63.

2. Arnstein LH, Boldrey E, Naffziger HC. A case report and survey of brain tumors during the neonatal period. J Neurosurg. 1951 May;8(3):315-9.

3. Buetow PC, Smirniotopoulos JG, Done S. Congenital brain tumors: a review of 45 cases. AJR Am J Roentgenol. 1990 Sep;155(3):587-93.

4. Raskind R, Beigel F. Brain tumors in early infancy--probably congenital in origin. J Pediatr. 1964 Nov;65:727-32. 
Jatorrizko artikulua

5. Sugimoto M, Kurishima C, Masutani S, Tamura M, Senzaki H. Congenital Brain Tumor within the First 2 Months of Life. Pediatr Neonatol. 2015;56(6):369-75.

6. Sato O, Tamura A, Sano K. Brain tumors of early infants. Childs Brain. 1975;1(2-3):121-5.

7. Hinojosa J, Esparza J, Muñoz MJ, Muñoz A. Tumores cerebrales congénitos: presentación de nueve casos y revisión de la literatura. Neurocirugía. 2003;14(1):33-40.

8. Di Rocco C, lannelli A, Ceddia A. Intracranial tumors of the first year of life. A cooperative survey of the 1986-1987 Education Committee of the ISPN. Childs Nerv Syst. 1991 Jun;7(3):150-3.

9. Rickert $\mathrm{CH}$, Probst-Cousin S, Gullotta F. Primary intracranial neoplasms of infancy and early childhood. Childs Nerv Syst. 1997 Oct;13(10):507-13.

10. Ventureyra EC, Herder S. Neonatal intracranial teratoma. Case report. J Neurosurg. 1983 Nov;59(5):879-83.

11. Wolff B, Ng A, Roth D, Parthey K, Warmuth-Metz M, Eyrich $M$, et al. Pediatric high grade glioma of the spinal cord: results of the HIT-GBM database. J Neurooncol. 2012 Mar;107(1):139-46.

12. Young HK, Johnston H. Intracranial tumors in infants. J Child Neurol. 2004 Jun;19(6):42430.

13. Chung SK, Wang KC, Nam DH, Cho BK. Brain tumor in the first year of life: a single institute study. J Korean Med Sci. 1998 Feb;13(1):65-70.

14. Zuccaro G, Taratuto AL, Monges J. Intracranial neoplasms during the first year of life. Surg Neurol. 1986 Jul;26(1):29-36.

15. Larouche $V$, Huang A, Bartels $U$, Bouffet $E$. Tumors of the central nervous system in the first year of life. Pediatr Blood Cancer. 2007 Dec;49(7 Suppl):1074-82.

16. Haddad SF, Menezes AH, Bell WE, Godersky JC, Afifi AK, Bale JF. Brain tumors occurring before 1 year of age: a retrospective reviews of 22 cases in an 11-year period (19771987). Neurosurgery. 1991 Jul;29(1):8-13.

17. Jooma R, Hayward RD, Grant DN. Intracranial neoplasms during the first year of life: analysis of one hundred consecutive cases. Neurosurgery. 1984 Jan;14(1):31-41.

18. Duffner PK, Krischer JP, Burger PC, Cohen ME, Backstrom JW, Horowitz ME, et al. Treatment of infants with malignant gliomas: the Pediatric Oncology Group experience. J Neurooncol. 1996 Jun;28(2-3):245-56.

19. Olischar M, Stavroudis T, Karp JK, Kaufmann WE, Theda C. Medical and ethical challenges in the case of a prenatally undiagnosed massive congenital brain tumor. J Perinatol Off J Calif Perinat Assoc. 2015 Sep;35(9):773-5. 